\title{
STABILIZATION OF FLUOROINDATE GLASSES BY MAGNESIUM FLUORIDE AND OTHER HEAVY METAL FLUORIDES
}

\author{
B. J. Costa* \\ IFSC - USP - CP 369 - 13560-250 - São Carlos - SP \\ A. Soufiane \\ Full Spectrum, Inc. - 2515 Elwood Drive - Unit 108 - Ames - Iowa - 50010 - USA \\ Y. Messaddeq \\ IQ - UNESP - CP 355 - 14800-970 - Araraquara - SP
}

Recebido em 2/12/96; aceito em 17/4/97

\begin{abstract}
Indium fluoride-based glasses constitute a new generation of materials for applications in the midinfrared spectral range. Their extended transparency in the IR makes them attractive for use as optical fibers for CO laser power delivery and optical amplification. This paper firstly describes the spectacular stabilizing effect of $\mathrm{MgF}_{2}$ on the binary system $\mathrm{InF}_{3}-\mathrm{BaF}_{2}$. The investigation of the $\mathrm{InF}_{3}-\mathrm{BaF}_{2}-\mathrm{MgF}_{2}$ system led to samples up to $5 \mathrm{~mm}$ in thickness. Further optimization of this system was achieved by incorporation of limited amounts of other fluorides and resulted in increased resistence to devitrification. The second approach of this work was concerned to the investigation of the pseudo-ternary system $\mathrm{InF}_{3}-\mathrm{GdF}_{3}-\mathrm{GaF}_{3}$ at constant concentrations of $\mathrm{ZnF}_{2}-\mathrm{SrF}_{2}-\mathrm{BaF}_{2}-\mathrm{NaF}$. Several compositions were studied in this system. The samples presented a better thermal stability when compared to other families of fluoride glasses. Therefore, these glasses seem to be very promising for the fabrication of special optical fibers. Thermal data are reported.
\end{abstract}

Keywords: glass; fluoroindate; stabilization.

\section{INTRODUCTION}

The technology of fluoride glasses has been the subject of continuing developments for the last 20 years. In fact, fluorozirconate glass fibers, extensively studied, have reached the level of industrial production with spectral losses as low as $10 \mathrm{db} / \mathrm{km}^{1}$. However, the intrinsic optical properties of fluorozirconate glasses limit transmission of wavelenghts longer than $4.5 \mu \mathrm{m}$, with acceptable attenuations less than $1 \mathrm{db} / \mathrm{km}$, through optical fibers.

Indium fluoride glasses exhibit good infrared transmission beyond that of fluorozirconates. One of their most attractive applications is in CO laser delivery. However, their high tendency to recrystallize makes fiber manufacturing a challenge. Improving stability is critical to production of high-quality preforms and optical fibers. Our goal, therefore, has been to develop an optimized indium-based fluoride glass composition and to minimize the formation of microcrystals during processing. We focused on stabilizing the basic $\mathrm{InF}_{3}-\mathrm{BaF}_{2}$ system with a number of additives (among the elements tested, magnesium fluoride seemed to improve glass stability more efficiently) and the pseudoternary $\mathrm{InF}_{3}-\mathrm{GdF}_{3}-\mathrm{GaF}_{3}$ system (with $\mathrm{ZnF}_{2}-\mathrm{SrF}_{2}-\mathrm{BaF}_{2}-\mathrm{NaF}$ ).

\section{EXPERIMENTAL PROCEDURE}

The glass samples described in this paper were prepared in air atmosphere using the ammonium bifluoride process ${ }^{2}$. An excess of $\mathrm{NH}_{4} \mathrm{HF}_{2}$ was added to the desired amount of oxides $\left(\mathrm{In}_{2} \mathrm{O}_{3}\right.$, $\left.\mathrm{Ga}_{2} \mathrm{O}_{3}\right)$ and fluorides $\left(\mathrm{BaF}_{2}, \mathrm{MgF}_{2}, \mathrm{ZnF}_{2}, \mathrm{SrF}_{2}, \mathrm{NaF}\right)$ and heated around $300^{\circ} \mathrm{C}$ to allow the conversion of the oxides to fluorides. The temperature was then gradually increased up to $500^{\circ} \mathrm{C}$ to eliminate the excess of fluorinating agent. Melting and fining were carried out in a deep platinum tube crucible, at $750^{\circ} \mathrm{C}$ and $800^{\circ} \mathrm{C}$ respectively, to reduce atmospheric hydrolysis of the melt. After

* Permanent address: Tecpar - CP 357 - 80001-970 - Curitiba - PR fining, the melt was poured in a brass mold preheated at $260^{\circ} \mathrm{C}$ and annealed below the glass transition temperature ( $\mathrm{Tg}$ ) of each sample, according to table I, for several hours.

\section{RESULTS AND DISCUSSION}

\subsection{Ternary system Ga-In-Ba}

The existence of glassy materials in the binary systems $\mathrm{GaF}_{3}$ $\mathrm{BaF}_{2}{ }^{3}$ and $\mathrm{InF}_{3}-\mathrm{BaF}_{2}{ }^{4}$, suggested combining these systems to improve their stability. Stabilization of the binary system by gallium fluoride led to only a limited success, resulting in samples requiring high cooling rates. Typical characteristic temperatures $\left({ }^{\circ} \mathrm{C}\right)$ of glasses in this system are reported in table 1.

Table 1. Characteristic temperatures of Ga-In-Ba glasses $\left({ }^{\circ} \mathrm{C}\right)$.

\begin{tabular}{cccc}
\hline Composition $(\mathrm{mol} \%)$ & $\mathrm{Tg}$ & $\mathrm{Tx}$ & $\mathrm{Tc}$ \\
\hline $10 \% \mathrm{Ga}-50 \% \mathrm{In}-40 \% \mathrm{Ba}$ & 320 & 394 & 400 \\
$40 \% \mathrm{Ga}-20 \% \mathrm{In}-40 \% \mathrm{Ba}$ & 364 & 438 & 447 \\
$60 \% \mathrm{Ga}-10 \% \mathrm{In}-30 \% \mathrm{Ba}$ & 388 & 430 & 436 \\
\hline
\end{tabular}

$\mathrm{Tg}=$ Glass transition, $\mathrm{Tx}=$ Onset of crystallization, $\mathrm{Tc}=$ Crystallization peak

\subsection{Ternary system Mg-In-Ba}

Magnesium fluoride has been incorporated previously in fluoride glass systems, such as fluoroaluminate and fluorozirconate, by Poulain ${ }^{5}$. In this work, we extended the investigation to magnesium fluoride in indium-based glasses, testing for effect as a stabilizer. The unusual stability of these glasses, rarely reported in fluoride ternary systems, led to the fabrication of samples as thick as $5 \mathrm{~mm}$. The improved thermal stability of glasses in this system and their ability to accomodate up to $20 \%$ (in mole) of magnesium allowed us to study the compositional 
dependence of their thermal and physical properties. Samples of $4 \mathrm{~mm}$ in thickness were prepared following the composition rule:

$$
\mathrm{xMgF}_{2}-(60-\mathrm{x}) \mathrm{InF}_{3}-40 \mathrm{BaF}_{2}
$$

Differential Scanning Calorimetry (DSC - TA Instruments 2910) was used at a heating rate of $10^{\circ} \mathrm{C} / \mathrm{min}$ to determine the characteristic temperatures of glasses in this system. Figure 1 describes the evolution of $\mathrm{Tg}$ (glass transition temperature), Tx (onset of first crystallization) and Tc (peak of crystallization), as a function of magnesium content.

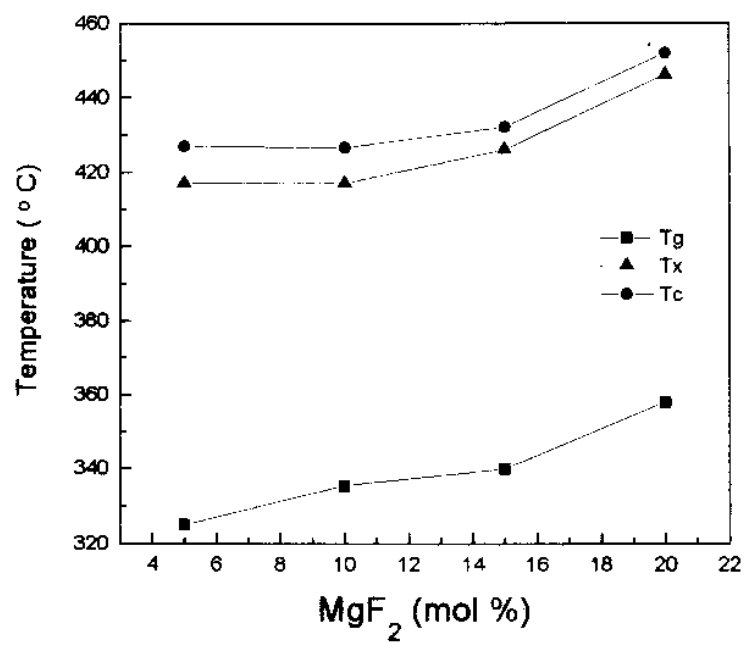

Figure 1. Evolution of Tg, Tx and Tc as a function of magnesium content.

In practice it is essential to minimize surface and bulk devitrification during fiber drawing or manufacturing of optical components. The parameter $(\mathrm{Tx}-\mathrm{Tg})$ is widely used as a quantitative scale for the assessment of the resistance of glasses against devitrification. This difference describes roughly the stability range of the glass and there are various examples ${ }^{6-8}$ which show that it varies continuously versus composition parameter and reaches a maximum value in a composition range which appears to give best glasses. An other stability criterion proposed by Saad and Poulain ${ }^{9}, \mathrm{~S}=(\mathrm{Tx}-\mathrm{Tg})(\mathrm{Tc}-\mathrm{Tx}) / \mathrm{Tg}$, takes in account the width of crystallization peaks in DSC experiments. According to such criterion, more stable glasses exhibit broader exotherms. As DSC scans are carried out at a constant heating rate, peak width is directly related to the time necessary for crystallization. Thus a broader peak corresponds to a larger crystallization time and therefore to a smaller crystallization rate. Glass stability in the $\mathrm{Mg}$-In-Ba system was compared to that of Ga-In-Ba glasses using the (Tx-Tg) and $\mathrm{S}$ criteria (table 2). The values of these parameters for typical compositions in both systems show the superior estimated stability of magnesium-doped glasses over those doped with gallium fluoride.

Table 2. Thermal characteristics of $\mathrm{Mg}-\mathrm{In}-\mathrm{Ba}-\mathrm{M}(\mathrm{M}=\mathrm{Mg}, \mathrm{Ga})$ glasses.

\begin{tabular}{|c|c|c|c|c|c|}
\hline \multicolumn{4}{|c|}{ Composition $(\mathrm{mol} \%)$} & \multirow[b]{2}{*}{$\mathrm{Tx}-\mathrm{Tg}$} & \multirow[b]{2}{*}{$\mathrm{S}\left({ }^{\circ} \mathrm{C}\right)$} \\
\hline In & $\mathrm{Ba}$ & $\mathrm{Mg}$ & $\mathrm{Ga}$ & & \\
\hline 55 & 40 & 5 & - & 92 & 2.83 \\
\hline 47.5 & 37.5 & 15 & - & 96 & 2.27 \\
\hline 45 & 35 & 20 & - & 94 & 1.94 \\
\hline 50 & 40 & - & 10 & 74 & 1.39 \\
\hline 20 & 40 & - & 40 & 74 & 1.86 \\
\hline 10 & 30 & - & 60 & 42 & 0.65 \\
\hline
\end{tabular}

\subsection{Pseudo-ternary system In-Gd-Ga}

The pseudo-ternary system $\mathrm{InF}_{3}-\mathrm{GdF}_{3}-\mathrm{GaF}_{3}$, at constant concentrations of $\left(\mathrm{ZnF}_{2}-\mathrm{SrF}_{2}-\mathrm{BaF}_{2}-\mathrm{NaF}\right)$ had several compositions investigated by Soufiane ${ }^{10}$ so as to determine the stabilizing effect of gadollinium fluoride in fluoroindate glasses. In this work, new compositions in this system, with different contents of In, Gd and $\mathrm{Ga}$, were tested and revealed a better thermal stability than that of glasses from the systems previously studied. Here, the $(\mathrm{Tx}-\mathrm{Tg})$ and $\mathrm{S}$ criteria were used again to demonstrate the good resistance of these glasses against devitrification. Table 3 presents values of (Tx -Tg) and $\mathrm{S}$ for some of the compositions studied.

Table 3. Thermal characteristics of In-Gd-Ga glasses at constant concentrations of $\mathrm{Zn}-\mathrm{Sr}-\mathrm{Ba}-\mathrm{Na}$.

\begin{tabular}{|c|c|c|c|c|}
\hline \multicolumn{3}{|c|}{ Composition $(\mathrm{mol} \%)$} & \multirow[b]{2}{*}{$\mathrm{Tx}-\mathrm{Tg}$} & \multirow[b]{2}{*}{$\mathrm{S}\left({ }^{\circ} \mathrm{C}\right)$} \\
\hline In & $\mathrm{Ga}$ & $\mathrm{Gd}$ & & \\
\hline 22 & 15 & 5 & 105 & 13.3 \\
\hline 35 & 5 & 2 & 109 & 6.9 \\
\hline 27 & 10 & 5 & 119 & 7.8 \\
\hline
\end{tabular}

The investigation of this particular system indicated that a criterious control of the contents of $\mathrm{GdF}_{3}$ and $\mathrm{GaF}_{3}$ is essential for the production of glasses with a high thermal stability.

\section{CONCLUSION}

To create a feasible basis for application of $\mathrm{InF}_{3}$ in fiber production, the improvement of thermal stability is a critical parameter. Gallium fluoride was first tested as a stabilizer in the In-Ba system, resulting in limited improvement in glass stability. Based on preliminary results, it was antecipated that doping of indium-based glass with a small percentage (up to $5 \%$ ) of magnesium would improve stability and chemical durability ${ }^{11}$. Comparison of resistance against devitrification of both glass systems showed superior stabilizing effect of magnesium over gallium. In addition, new compositions in the pseudo-ternary system In-Gd-Ga demonstrated to have a better thermal stability than that of the glasses from the other systems investigated in this work. Such stability depends on a criterious control of the contents of $\mathrm{GdF}_{3}$ and $\mathrm{GaF}_{3}$ in the compositions. These results demonstrate that those glasses are promising for the fabrication of special fibers, under the point of view of thermal stability.

\section{REFERENCES}

1. Mazé, G.; Cardin, V.; Chiquet, F. ; Poulain, M.; Springer Proc. in Phys. 1989, 44, 20.

2, Poulain, M. ; Mazé, G.; Chemtronics 1988, 3, 77.

3. Soufiane, A. ; Poulain, M.; J. Non-Cryst. Sol. 1993, $161,206$.

4. Videau, J. J. ; Dubois, B.; Portier, J.; C. R. Acad. Sci. Paris 1983, 297, 483.

5. Poulain, M. ; Poulain, M.; J. Non-Cryst. Sol. 1992, 140, 87.

6. Soufiane, A.; Poulain, M.; J. Non-Cryst. Sol. 1993, 161, 206.

7. Delben, A.; Ph. D. Thesis, 1992, IFQSC - USP, São Carlos, SP.

8. Messaddeq, Y.; Poulain, M.; J. Non-Cryst. Sol. 1992, 140, 41.

9. Saad, M.; Poulain, M.; Mater. Sci. Forum 1987, 19, 11.

10. Soufiane, A.; Ph. D. Thesis, Universite de Rennes I, Rennes, France 1992, 79.

11. Costa, B. J.; Soufiane, A.; Messaddeq, Y.; Proc. Intern. Symp. On Glass Cryst. 1996, November 4-8, Florianopolis, SC, Brazil. 